Ittishal Educational Research Journal January 2021, Vol. 2, No. 01, p. 01 - 10 http://journal.ittishal.net/index.php/ierj

DOI 10.51425/ierj.v2i1.19

\title{
Arabic Teaching Methods for Non-Native Speakers: Types, Advantages, and its Application in Indonesia
}

\author{
Sangidu \\ Universitas Gadjah Mada, Indonesia \\ sangidu@ugm.ac.id
}

\begin{abstract}
The problem of learning Arabic for non-native speakers in Indonesia is influenced by two factors; linguistic factors and non-linguistic factors. Linguistic factors include phonology, morphology, syntactic, and vocabulary. Meanwhile, non-linguistic factors include social, culture, motivation, methods, learning environment and so forth. This paper discusses the problems of learning Arabic for non-native speakers in Indonesia, the types of methods, its advantages, and its application. The results of the study conclude that Islamic boarding schools, Islamic schools, and campuses that carry out Arabic lessons need to provide native speakers from Arab countries or send students to Arab countries.
\end{abstract}

Keywords. non-native Arabic speakers; Arabic teaching methods; linguistic factors; non-linguistic factors 
يف اهتاقيبطتو اهايازمو اهعاونا :اهب نيقطانلا ريغز ةيبرعلا :غلرا سيردت قرط اي سين ودن!

\section{IJjで}

لعاوعلا امهو ، نيلماعب اهب نيقطانلا ري غل ةيبرعلا مغلا ملعت ةلكشم رثأتت ،فرصلاو ،تاوصألا ملع لثم ةي وغللا لكاشملا لمشت.تيوعزلا ريع لماوعلاو تيوعزلا

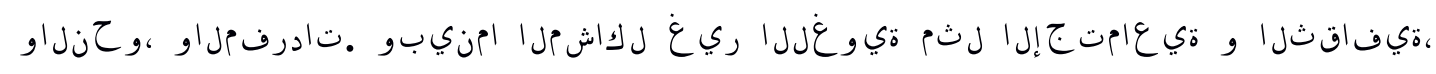

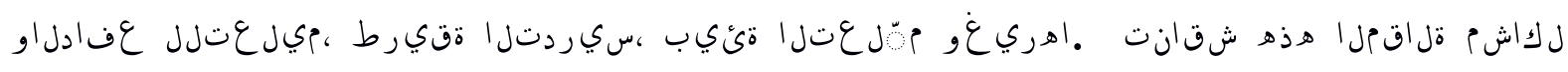

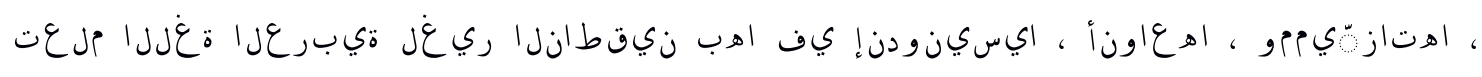
مدقت يتلا تاعماجلاو سرادملاو ةيمالسإل دهاعملا نأ ةساردلا جئاتن رهظت .اهقيبطتو لاسرا وا ةيبرعلا لودلا نم نيقطانلا ريفوت ىلإ جاتحت ةيبرعلا مغلا يف اذَّورد

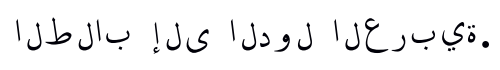

ة عزلا سيردت قرط ، اهب نيقطانلا ري غز ةيبرعلا ، ميبرعلا :تيحاتفملا تاملكل ايسينودن! ، ميبرعا 


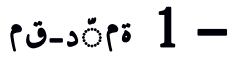

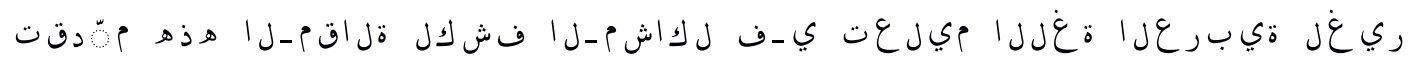

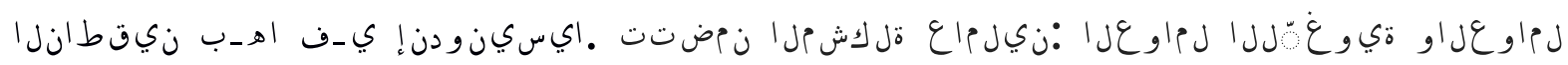
تاوصأل ال ع لثم ةي وغلرا لكاشعلا لمشتو .روفلا ىلع اهلح بجـي يتلا ةيوعزلا ريغ

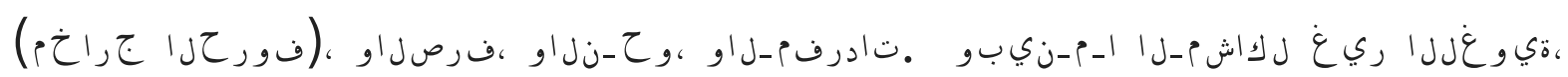

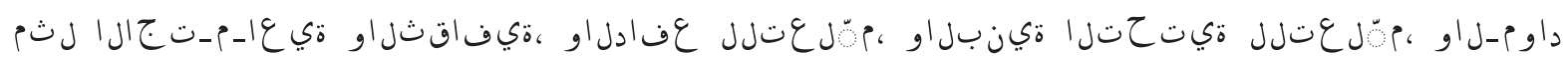

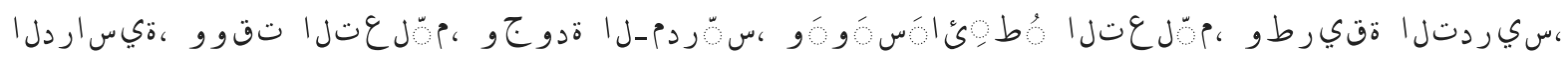

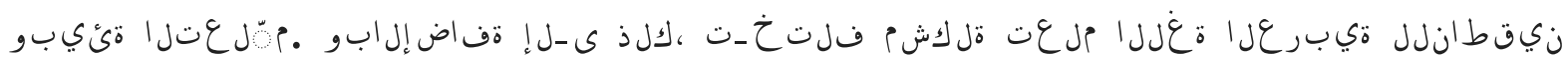

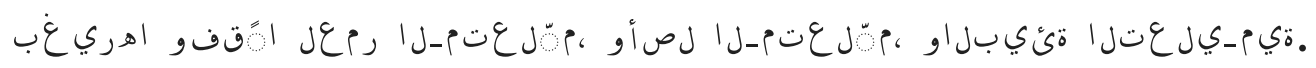

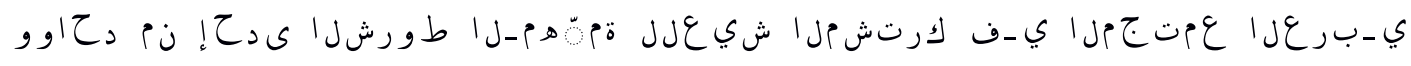

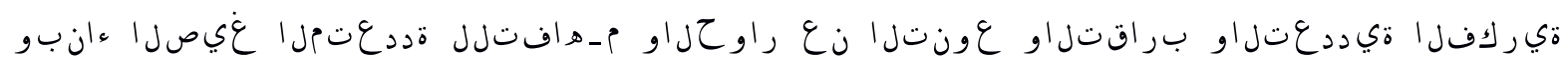

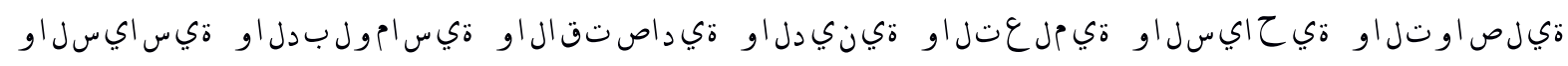

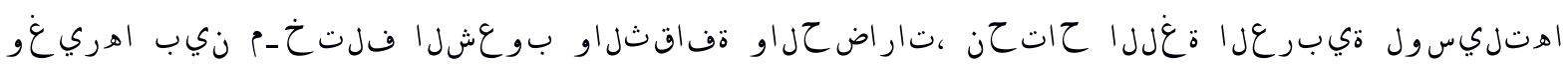

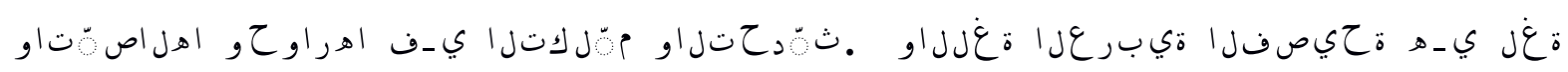

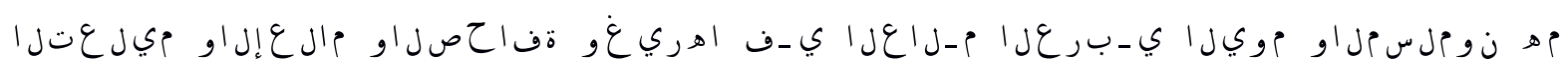

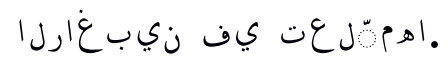

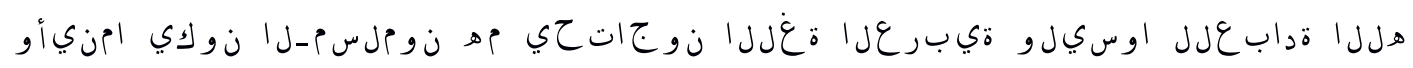

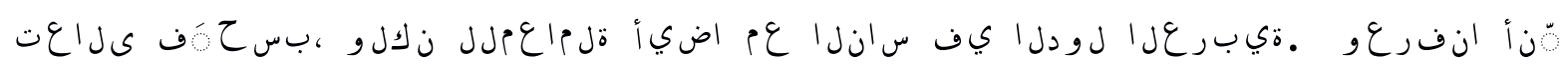
اي (Malaysia)

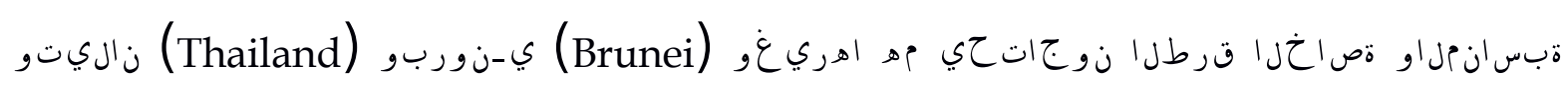

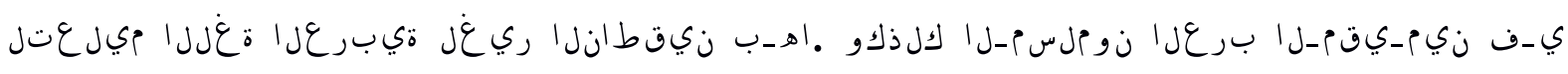

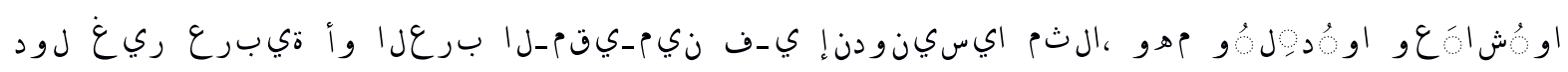

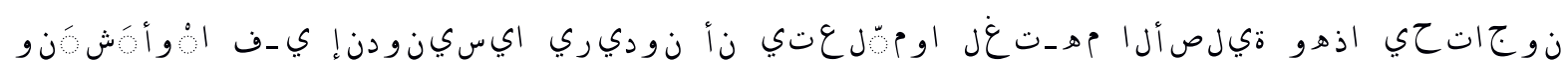

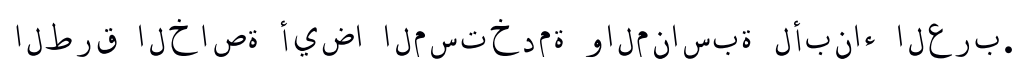

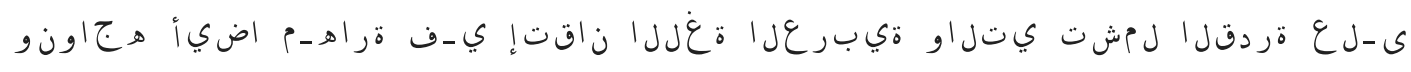

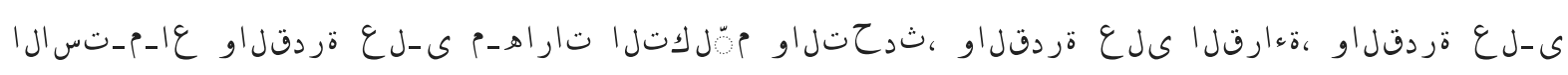

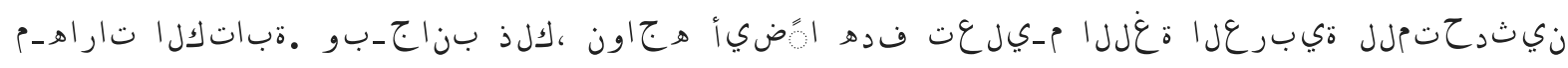




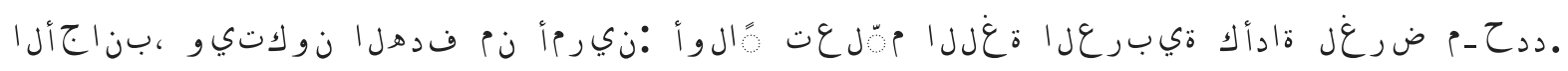
ة غلرا مّّل تايناثو .كلذ ريعو ،نيثحابلاو نيمّلعملا اوحبصأ مهنمف فدهلا اذهبو

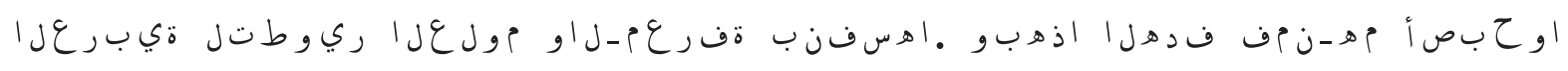

•كلذ ري غو ،مالسإل نيدل نيقمعتملا ،راجّتل ا نزيسامولبدلا

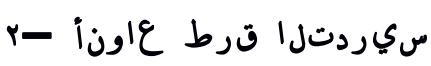

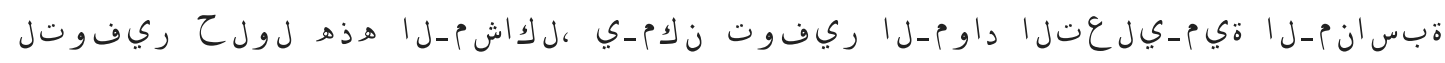

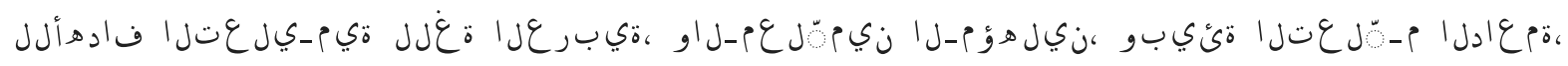

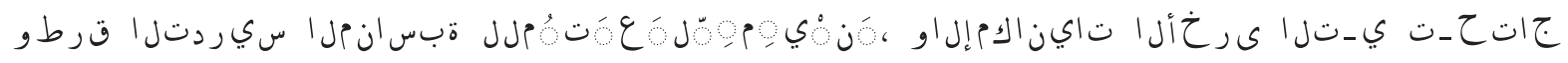

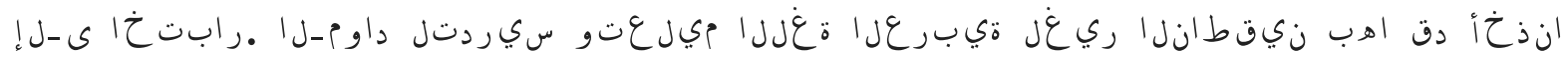

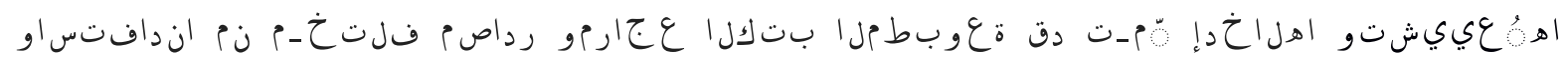

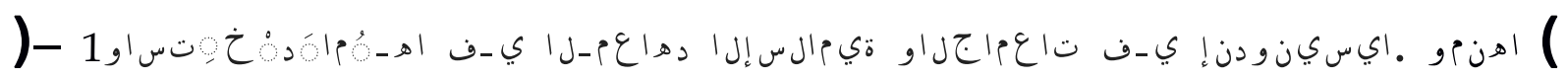

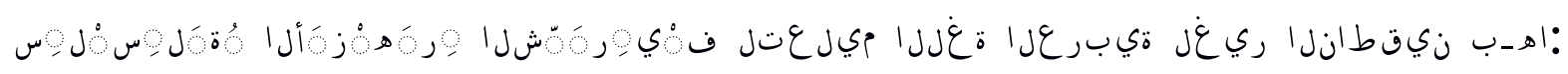

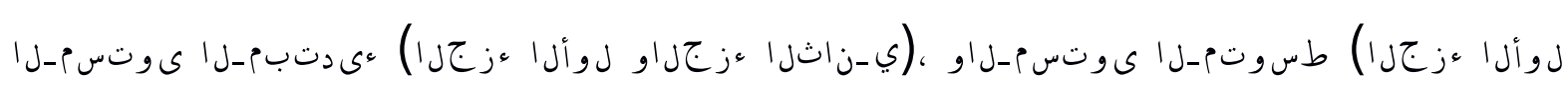

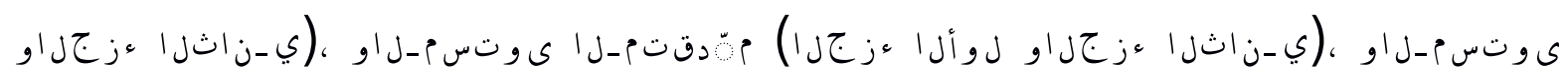

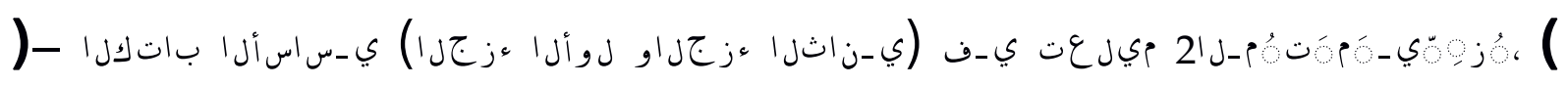

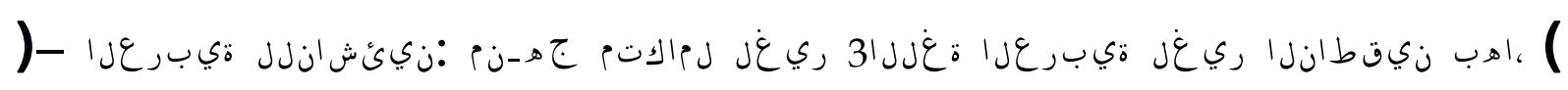

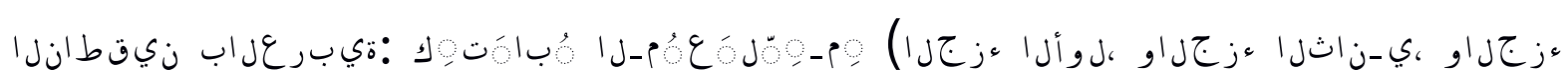

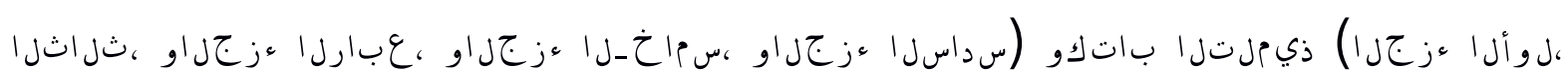

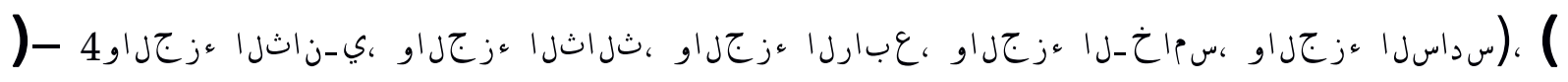
:اهــب نيقطانلا ريعز ةيبرعلا ةغرلا ميلعت ي-ف ةلسلس :كبدي نيب ةيبرعلا

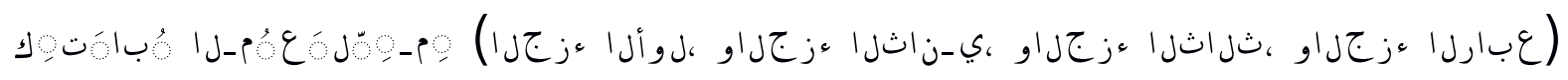

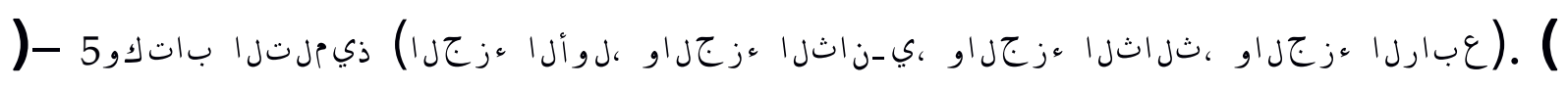

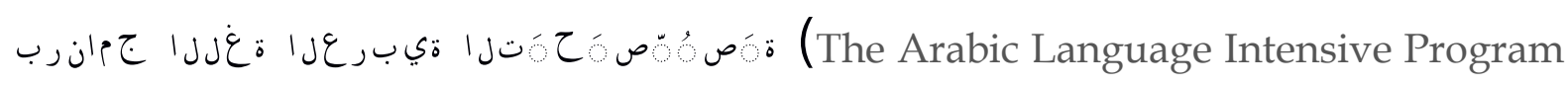

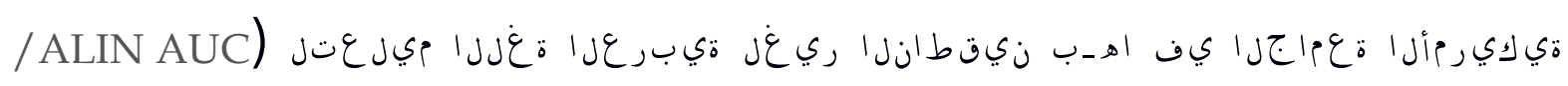

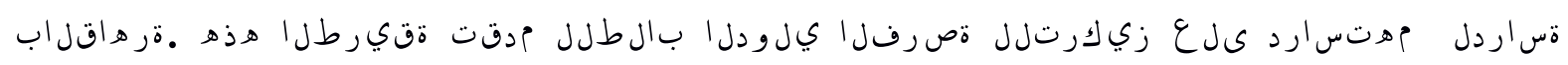




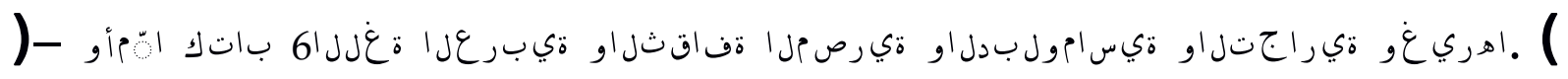

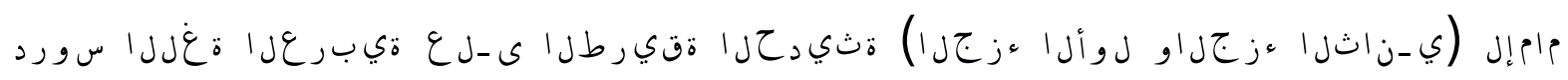

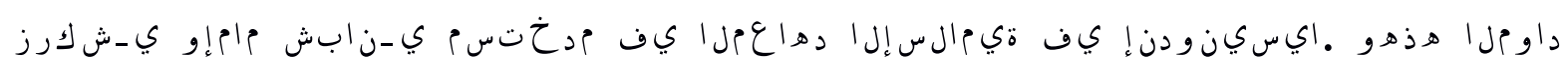

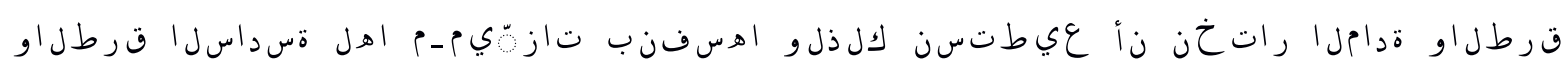

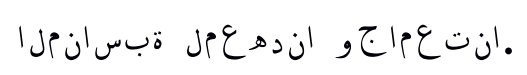

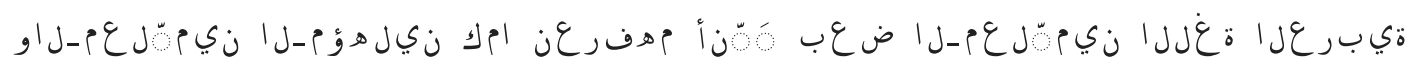

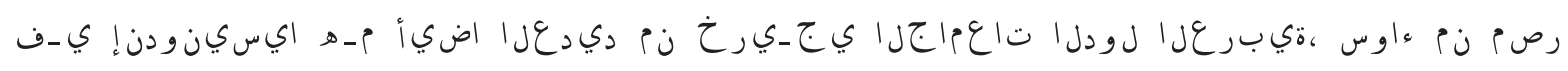

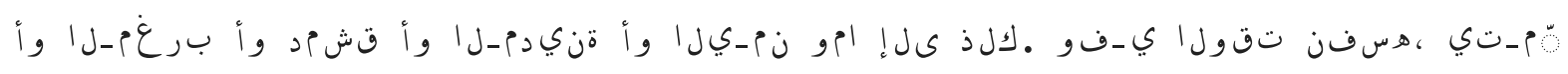

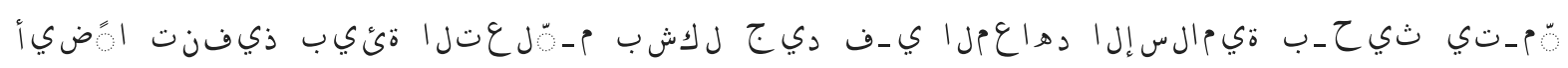

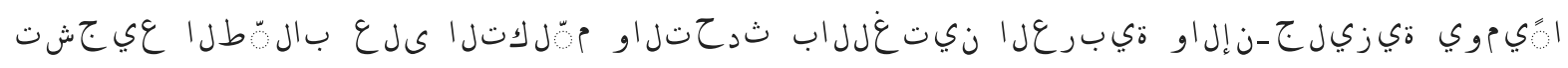

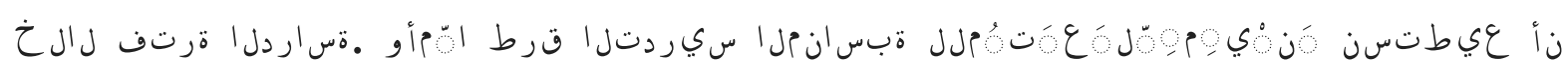
ا

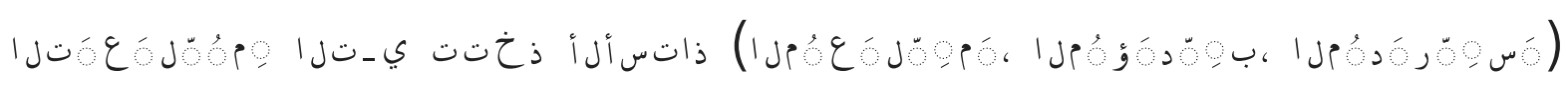

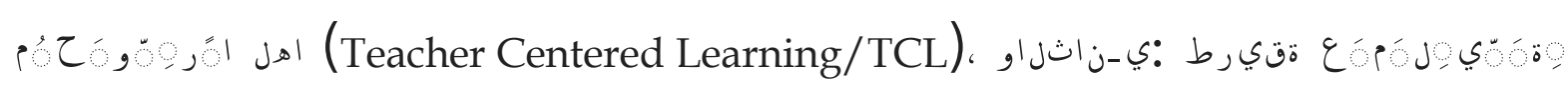

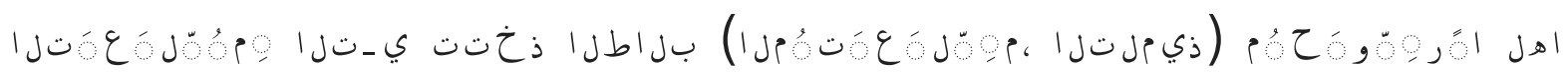

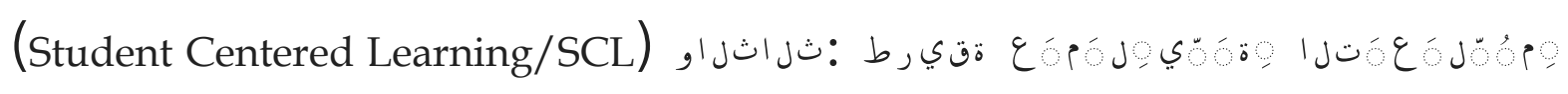

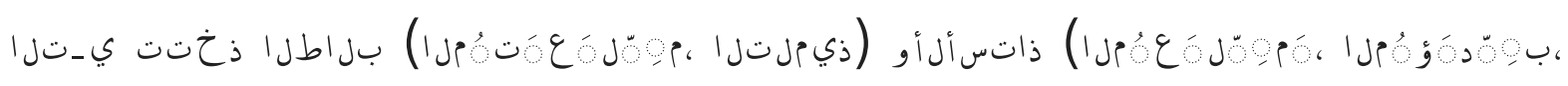

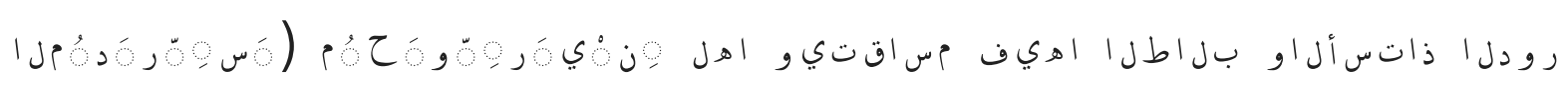
قر طرا هذهـو (Student-Teacher Aesthetic Role Sharing /STARS). اندهوعل ةبسانعلا ةقيرطل| راتخن نأ عيطتسن لكلذو اهسفنب تازّيم-م اهل مسداسل|

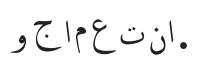

\section{r -}

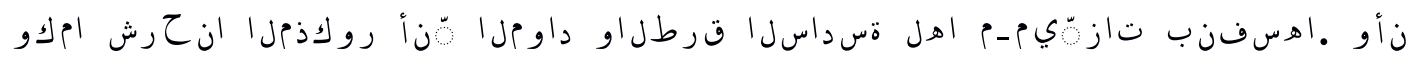

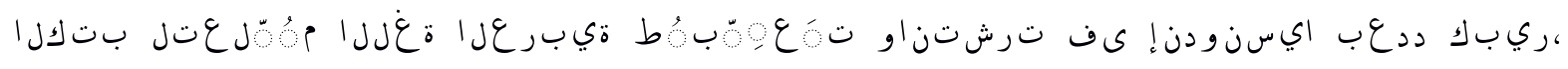

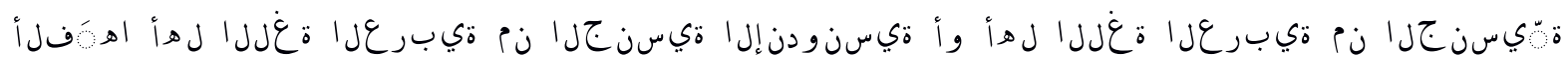

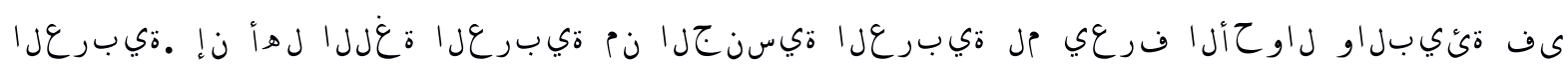


ىف ةعونتملا بتكلا مهف ىف نيسسنودنإلا بالطرا ةبوعص ىل! ببسي اذهو ايسنودن!

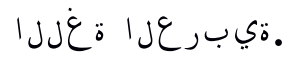

\section{ع -}

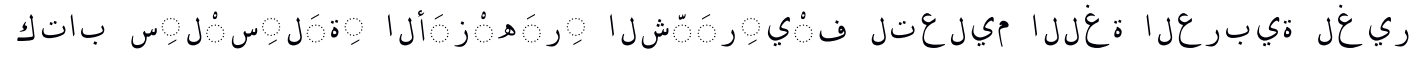

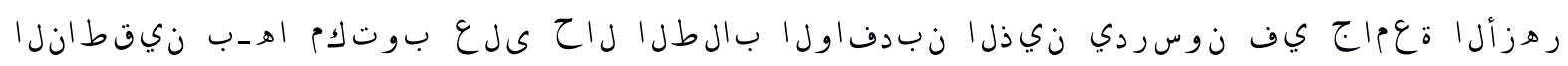
مدختسم باتكلا اذهو .ةيرصعلا ةفاقثلاو ةعماجلا ةئيب ىلع هتباتك دمتعتو فيرشلا

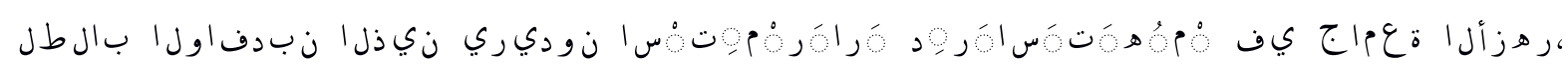
رضاحملا عالك عهف ىف ةبوعصلا نودجي اونالك بالطرا مه . ميبرعلا رصم ميروهمج نأ بجي عهنم ،ةيوعزلا مهتردق بسح بالطرا اهكرتشي ةرودل هذهه .ةعماجلا سورد مهفو ة ماك ةنس وأ ،روهشلا ةتس وأ ،روهشلا مثالث ىف ةردلا عُم علعتي.

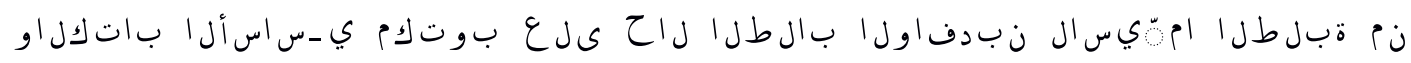

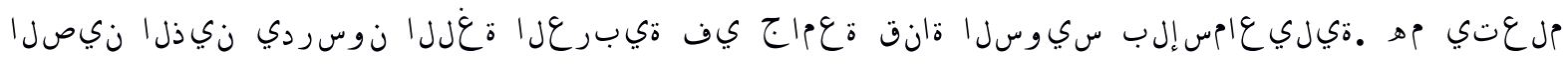

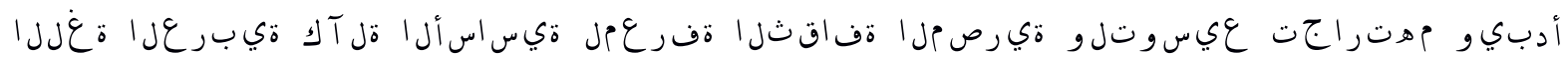

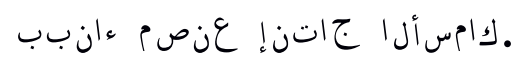

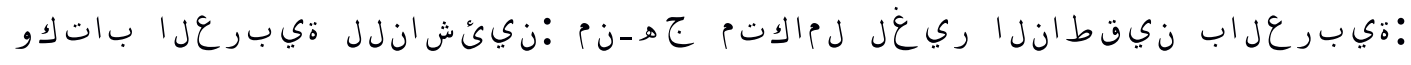

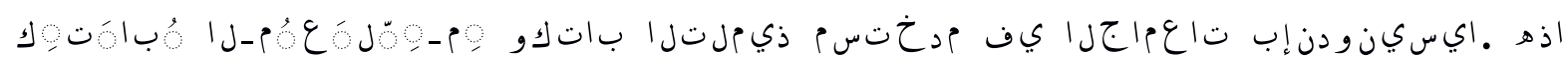

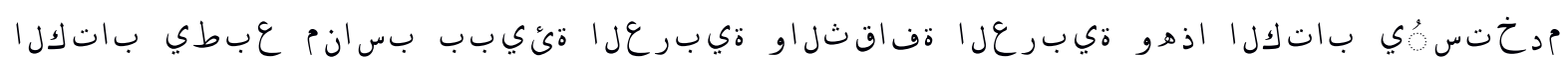

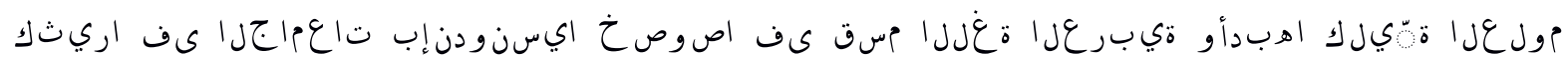

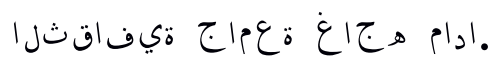
ري غل ةي برعلا مغلرا ميلعت ي-ف ةلسلس :كي دي نيب ةيبرعلا باتكو

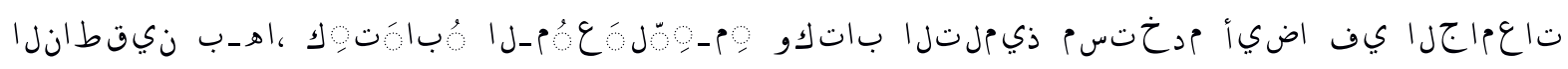

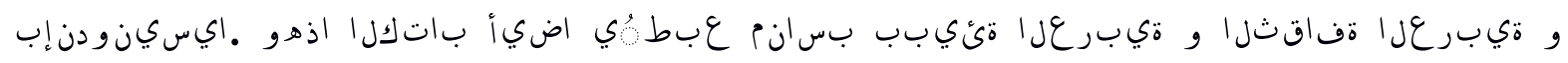
ةيبرعلا ةغللا مسق ىف اصوصخ ايسنودن إب تاعماجلا ىف اريثك مدختسُي باتكلا اذه

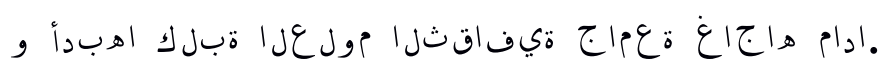




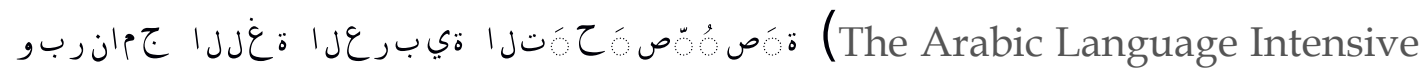
بوت بـ Program /ALIN AUC) ةعماجلا يف ةيبرعلا ةغلا نوسردي ني ذلا ةيبرغلا لودلا نم نيدفاولر عدختسمو

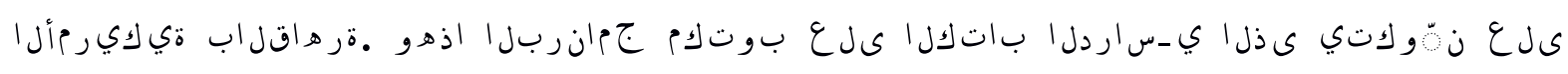
زيكرتلاو ةي برعزا ةفاقثلاو ةيرص علا ةفاقثلا ىلع هتباتك دمتعتو .عازجألا ةعبراً •اهريعو ةيراجتلاو ةيسامولبدلا لاجم يف ليصحتاو.

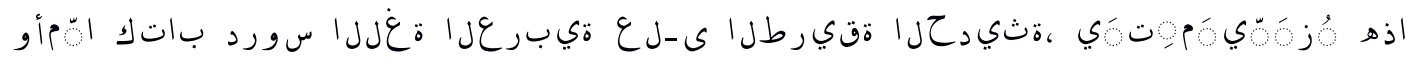

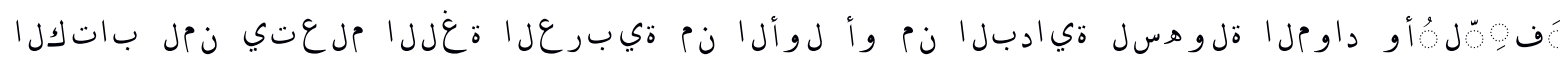

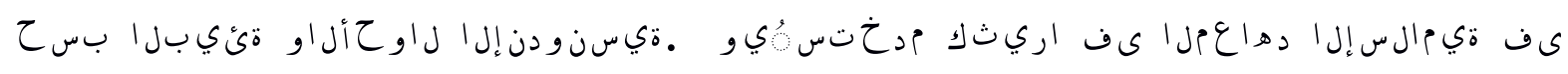
•ة قرشلا اواج وغورونوف روتنوغ مالسلا راد دهع ىف اصوصخ ايسينودنا!

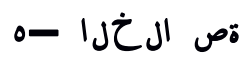

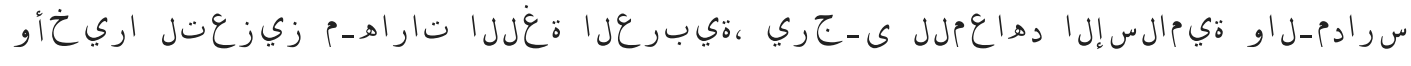

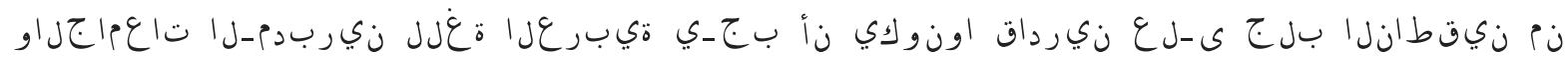

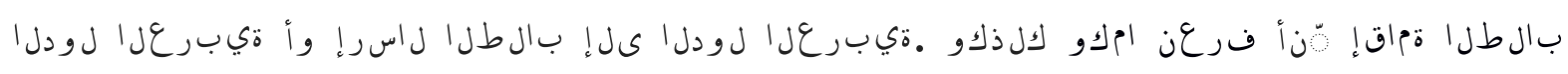

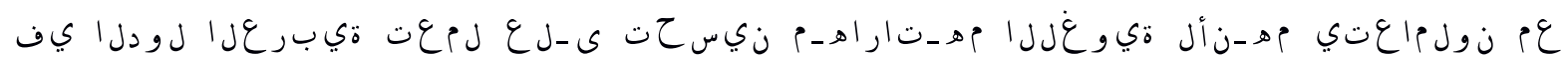

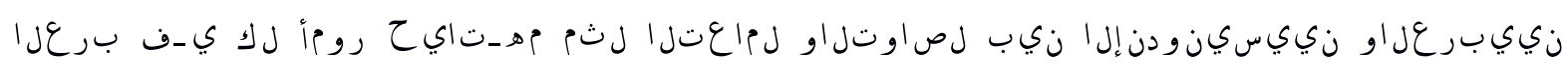

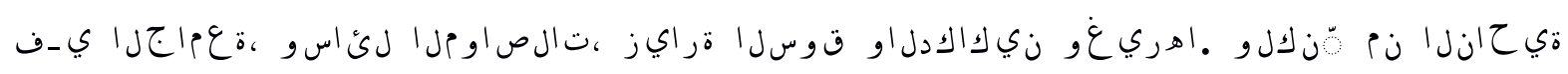

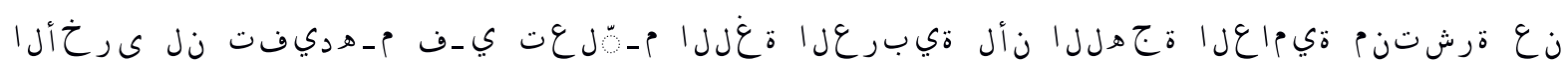

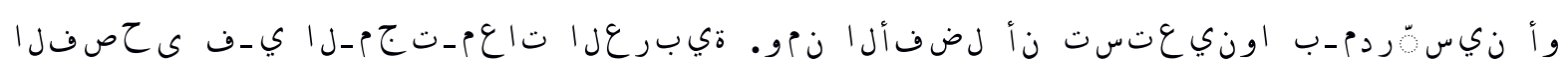

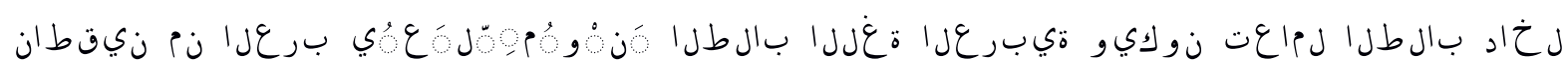

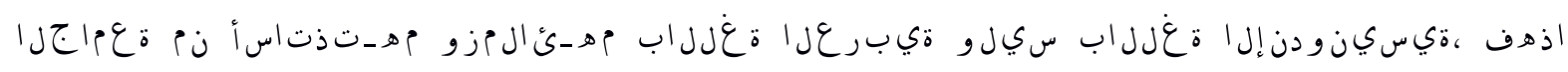

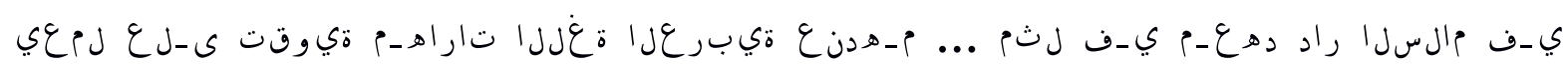

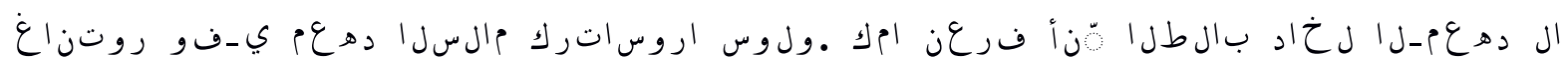

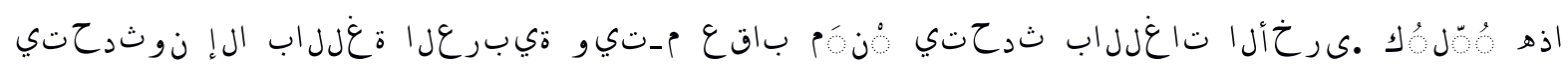

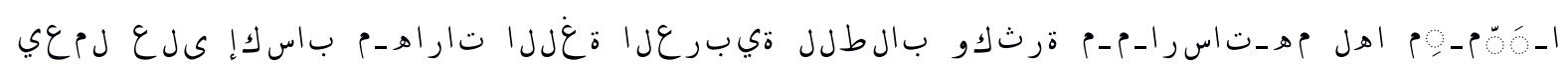




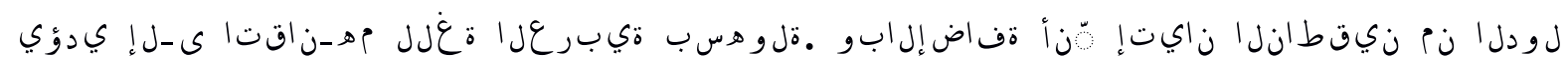
. 
|

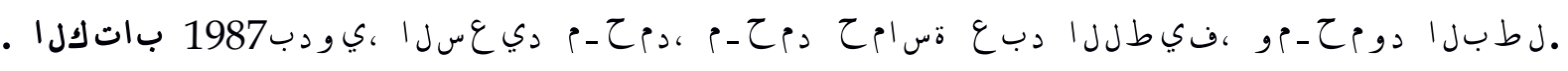

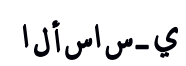

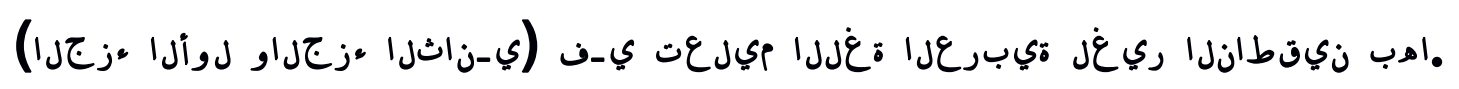
،بت كل| راد P.

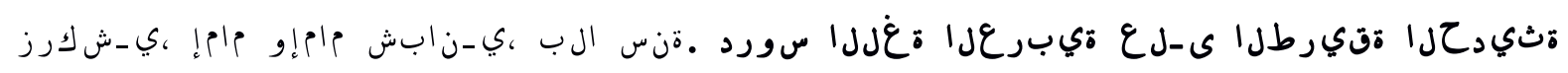
(נJجز وغ غورونوف .ةعابطلر ي-تروم يريت .(ي-ناثلا •زجراو لرألا

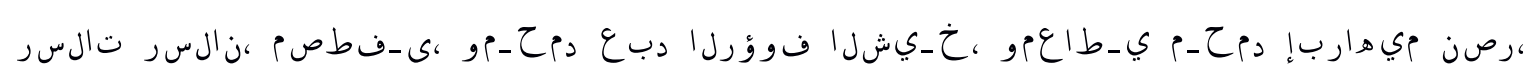

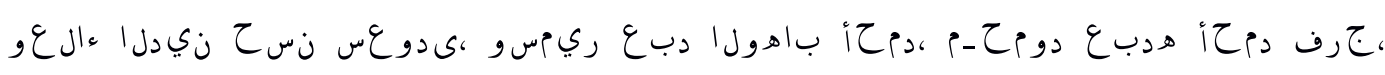

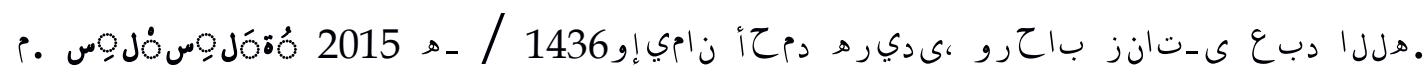

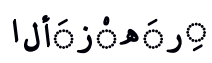

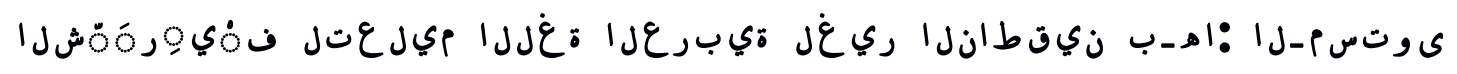

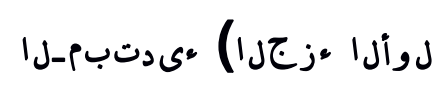

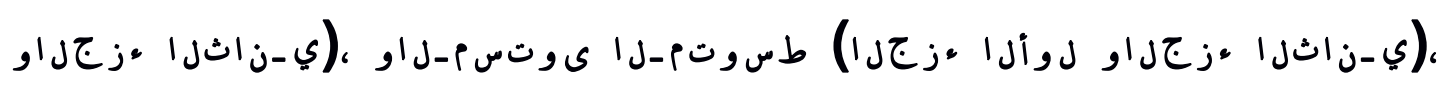
كوتمب-Jاو

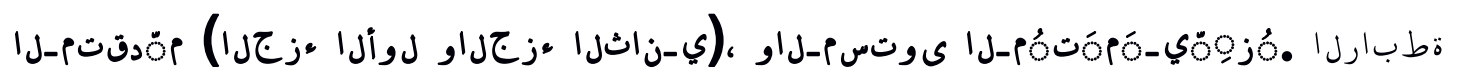

inglueso

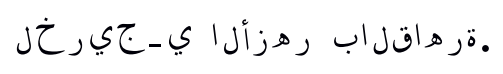

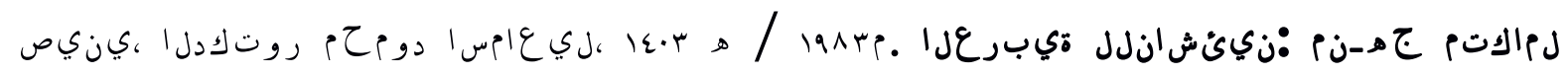
ري

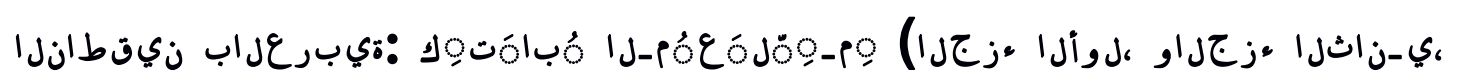

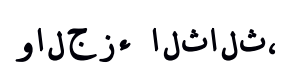

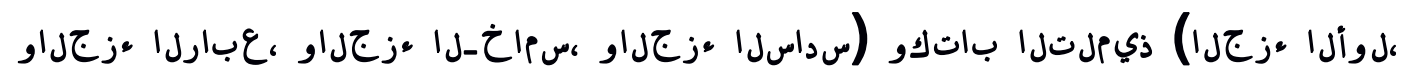




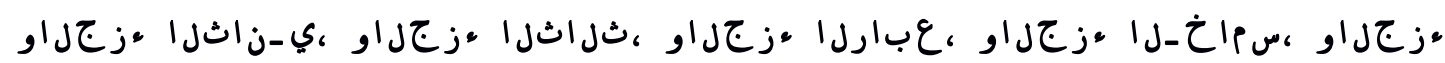
(سداسل).

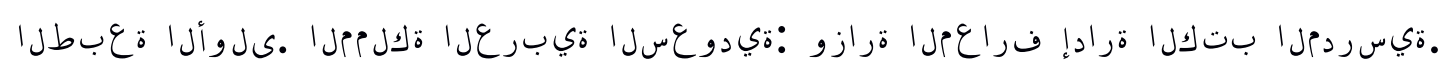

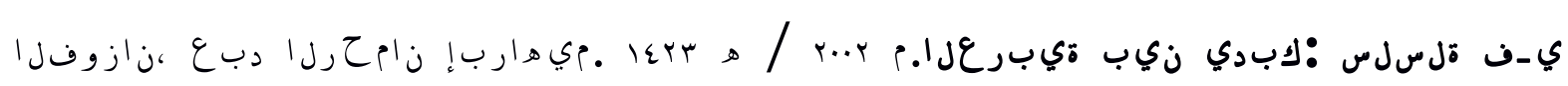
p

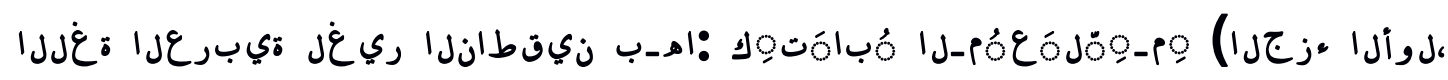

$$
\text { • }
$$

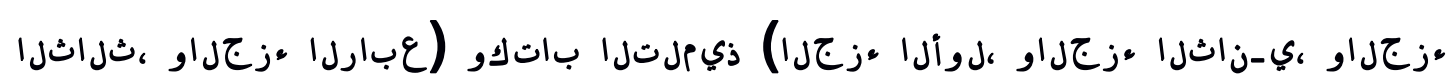

اثراث،

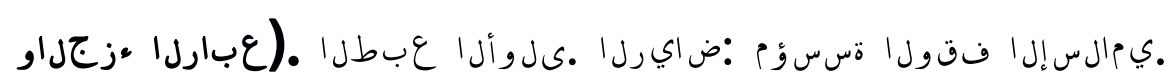

